\title{
Stereotypical Views of Beauty and Boys STILL Not Letting Girls Play: A Student-Centered Curriculum for Young Girls Through an After-School Activist Approach
}

\author{
Risto Marttinen \\ George Mason University California State University \\ Sara B. Flory \\ University of South Florida
}

\begin{abstract}
Purpose: The purpose of this study was to explore how a student-centered curriculum engaged participants in critical analysis of the "female ideal" and to identify perceived barriers to physical activity. Method: Participants were nine fifth and sixth grade Hispanic/ Latina or mixed race girls, and two researchers at an urban elementary school in Southern California. Participants met one to two times per week in an after-school program. Data sources included researcher and participant journals, field notes, and semistructured interviews. Trustworthiness and credibility were established through prolonged engagement, member checks, and peer reviewer. Results: Two themes permeated the data. The first theme involved boys acting as a barrier to physical activity. The second theme involved alignment with the ideal female body. Discussion: This study highlights how boys still act as barriers to girls' physical activity in many school settings, but also identifies how role models for girls have increased girls' ability to critically examine media messages.
\end{abstract}

Keywords: body image, elementary, empowerment, Latina, physical education

Issues of social justice and equity in physical activity (PA) contexts and school physical education (PE) have been prevalent for several decades. Researchers in PE and PA have examined inequities related to gender (e.g., Vertinsky, 1992); race (e.g., Azzarito \& Solomon, 2005); socioeconomic status (e.g., Quarmby \& Dagkas, 2013); urban schools (e.g., Cothran \& Ennis, 1999) and (dis)ability (e.g., Fitzgerald, 2005), as well as the intersection of these issues in a globalizing society (e.g., Azzarito, Macdonald, Dagkas, \& Fisette, 2017). These issues are not specific to PE or PA environments but exist in broader education and society at large due to systemic; institutional; historical; cultural forms; and forces of racism, sexism, inequality, and so forth (Azzarito \& Solomon, 2005; Vertinsky, 1992).

Many researchers have problematized these issues and identified how these issues prevent access and equality in PE and PA spaces. Previous research identifies how PE has been a space to reproduce gendered power relations and how the differing experiences for males and females in educational settings are problematic (Fisette, 2013; Vertinsky, 1992). In addition, while safety is a concern for all youth, young girls are faced with more safety concerns, specifically in relation to their "sexual safety and vulnerability" (Clark, 2015, p. 1013). Clark (2015) found that young girls were more confined and supervised in their PA spaces since parents conceptualized their daughters as vulnerable. This ultimately acted as a barrier for girls' PA due to greater restrictions set by their parents. However, young girls also have concerns for their safety when playing outside (Azzarito \& Hill, 2013; Clark, 2015).

Marttinen is with George Mason University, Fairfax, VA, USA. Meza is with the Department of Kinesiology, California State University, Fullerton, CA, USA. Flory is with the University of South Florida, Tampa, FL, USA. Marttinen (rmarttin@ gmu.edu) is corresponding author.
Girls have said that they would not engage in PA in areas that lacked feelings of safety, comfort, or protection (Azzarito \& Hill, 2013). Moreover, girls have expressed they experience barriers to PA in their PE classes because boys will not let them play (Oliver, Hamzeh, \& McCaughtry, 2009; Oliver \& Lalik, 2001). Girls may face even greater issues than just their barriers alone, as they must constantly survey their PA environment, even in the PE setting where girls should feel safe and be encouraged to engage in PA.

In addition to the previously mentioned barriers, other influences, such as the media, have affected the way girls approach or consider their PA in PE. Azzarito and Solomon (2006) found adolescent girls would engage in PA in their PE classes in order to obtain the ideal female body represented in the media. Although this does not represent a physical barrier to PA, it highlights how adolescent girls' PA is affected by gender stereotypes and the media's representation of the female body. This also suggests young girls are engaging in PA to achieve a certain aesthetic rather than for their physical health and well-being.

\section{Work With Girls Through Curriculum}

Many researchers have worked with young girls to identify perceived barriers to PA, how to navigate around those barriers, or change their perception and approach to PA. A widely used and effective approach in qualitative research is creating curricula as interventions and working with girls as coresearchers (Oliver \& Hamzeh, 2010) and active agents (Azzarito, Simon, \& Marttinen, 2016; Azzarito \& Solomon, 2006). In the following section, we highlight past research that has with preadolescent or adolescent girls in PE and PA settings.

Oliver and Lalik (2001) worked with adolescent girls using a curriculum that focused on the body. Through magazine exploration 
and several writing activities, the researchers were able to better understand the lived experiences of the young girls, specifically in relation to how the girls felt their body was noticed, accepted, and consequently regulated in their life. This study provided insight into the effectiveness of writing activities and how such activities can help girls reflect on issues related to the body. Similarly, Oliver and Lalik (2004) created a curriculum strand to help girls name and understand the discourses that influence their lives. Although the activities were at times confusing for the participants, the researchers found that the participants were eager to share their thoughts in group discussions and were able to develop critical analysis skills.

Oliver and Hamzeh (2010) worked with young girls as coresearchers to help identify perceived barriers to PA. One of the major barriers identified by all participants were the boys not letting girls play. Together as coresearchers, all individuals involved in the study were able to challenge the gendered discourses they experienced in their PE classes. In addition, Oliver et al. (2009) also found that boys did not allow girls to play. However, the researchers worked with participants to help them maintain their "girly girl" identity. At first, participants chose not to engage in PA because they did not want to get sweaty or dirty, and this would impede their "girly girl" embodiment. However, when participants could design their own activities that "girly girls" could play without compromising their identities, they chose to engage and participated with vigor-even getting sweaty and dirty. The researchers worked to establish an environment where the participants could be physically active without compromising any of the elements that cemented their status as a girly girl (i.e., being physically active but not liking sports).

Luguetti et al. (Luguetti, Oliver, Kirk, \& Dantas, 2017) shared findings related to activist approach research in an after-school setting. Their research indicates the need to identify barriers to participation and imagine potential solutions that could realistically be cocreated. More recently, research using an activist approach has been successful especially when working with girls. Lamb, Oliver, and Kirk (2018) found that girls responded positively to choices and variety in PE classes that they designed with their teachers. In addition, the participants developed better relationships with their teachers, which increased their motivation and engagement in PE lessons. Walseth, Engebretsen, and Elvebakk (2018) claimed that female students found PE to be more meaningful when lessons were framed with an activist approach. The participants also shared that the safer environment afforded by the activist approach increased students' feelings of social inclusion during the study. Finally, a recent study by Azzarito, Simon, and Marttinen (2016) exemplified that through activities from a body curriculum, researchers observed that adolescents recognized the media's representation of gender stereotypes and ideal female bodies as harmful. Although participants engaged in critical analysis about the ideal female bodies represented in the media, the participants still showed an interest in achieving such bodies. These studies highlight the effectiveness of working with girls and using curricula as interventions to help participants engage in critical analysis to identify and navigate their barriers to PA. Many of these researchers utilized the activist approach and/or feminist poststructuralism as a theoretical framework to guide them through their research, both of which were utilized in this study and are described in the following section.

\section{Activist Approach With Feminist, Poststructuralist Lens}

In this study, we utilized an activist approach with a feminist, poststructuralist lens. According to Oliver and Kirk (2015), there are four critical elements to the activist approach: (a) studentcentered pedagogy, (b) creating spaces in curriculum for girls to focus on embodiment, (c) inquiry-based education centered in action, and (d) sustained listening and responding over time. The activist approach allows researchers to gain knowledge about issues that exist among young girls in the PE setting by working with participants (Oliver \& Kirk, 2015). Feminist poststructuralism provides researchers a canvas in which gendered, cultural, and racial discourses among girls can be dissected to understand how language affects individual experiences and how individuals express themselves (Gavey, 1989). As described by Azzarito and Solomon (2006), "feminist poststructuralist theoretical standpoints challenge and disrupt the unitary and essentialist body to free individuals' identity processes and acknowledge the body as a constructed, inconsistent, and fluid entity" (p. 203). Together feminist poststructuralism with an activist approach will allow us, as researchers, to further understand how participants' experiences are shaped by the discourses they experience. This gives researchers the opportunity to potentially break down those discourses by utilizing the critical elements of the activist approach to understand how and where gendered stereotypes and barriers to PA emerge and circulate.

Although research has been conducted to uncover barriers girls face to PA and innovative techniques and curricula have been employed to break down these barriers, there is still a palpable issue with girls' physical inactivity due to their perceived barriers and their desire to use PA to achieve a body type that aligns with the ideal female body (Azzarito, 2009). Therefore, the study at hand will explore how the Gaining Insight through Reflective Learning (GIRL) curriculum can engage girls in critical analysis of the ideal female body and help girls identify perceived barriers to PA. Thus, the research question guiding our inquiries was: What barriers do girls face in participating in PA in an urban after-school program?

\section{Method}

The GIRL programming and curriculum was developed from the Reflective Educational Approach to Character and Health (REACH) after-school program. REACH was implemented into the Sunset Elementary (names of schools and students are pseudonyms) after-school program during the 2016-2017 school year (1 year prior to this study). Volunteer coaches noticed that girls often brought up issues of body image during group discussions. In response, once REACH expanded to a second school, Waterfalls Elementary, during the 2017-2018 school year, the researcher decided to also include the GIRL curriculum.

\section{Setting}

Waterfalls Elementary (K-6) was selected as the site for the study through cooperation from district personnel responsible for afterschool programming. Waterfalls is located in an urban southern California school district and enrolled 399 students; $87 \%$ were Hispanic/Latino, 3.5\% White, 3.5\% Asian, 1.3\% Black, and the remaining population was comprised of American Indian or Alaska Native, Filipino, Pacific Islander, or were of two or more races. Waterfalls was considered a "Title I" school, serving a predominately low-income population determined by an unduplicated count of students $(81 \%)$ who were receiving free- or reduced-price lunch. The students were English language learners or were in foster care. There were 228 English language learners who attended Waterfalls, $96 \%$ of which were native Spanish speakers. There is 
no school-level data on the number of students who received special education services. The researchers implemented the REACH and GIRL curriculum concurrently and received permission to conduct research from the principal at Waterfalls Elementary and the district level after-school program coordinator. In addition, California State University, Fullerton and school board granted approval through their respective ethics boards.

\section{Participants}

Participants in the study included students and coaches. Both sets of participants contributed to data collected in the study.

Students. The researchers recruited fifth- and sixth-grade girls in the after-school program to participate in the study. Initially, 13 students volunteered, returned the required consent and assent forms, and were present for the first day of GIRL programming. Throughout the study, three students disenrolled from the schoolwide after-school program, and one student was not allowed to attend GIRL programming based on a decision from the after-school coordinator. This study focuses on nine participants who consistently participated in GIRL sessions during the school year. These participants were fifth and sixth graders aged 10 to11 years, and identified as Hispanic/Latina or mixed race. Most of the participants spoke both English and Spanish. One participant spoke only Spanish at the beginning of the study; however, began speaking English more throughout the year.

Coaches as researchers. Two participants served as the coaches and researchers in this study. The primary researcher, Bri, is female and of Latin/Hispanic descent but is frequently perceived as White. She identifies as Latina, middle-class, heterosexual, physically active, and able-bodied. This researcher is fluent in English and can understand some Spanish. She did not attend day care or afterschool programming as a child. The schools she attended prior to college were diverse, and many of her peers were in middle and high socioeconomic classes.

The second participant/coach, Olivia, acted mostly as a research assistant in the study. She was pursuing a bachelor's degree in PE, identified as Filipino-American, middle-class, heterosexual, physically active, and able bodied. She was a firstgeneration college student and spoke English and some Spanish. She never attended day care or an after-school program as a child. The schools she attended prior to college were diverse and were in communities of low socioeconomic status.

\section{Procedures}

The GIRL curriculum was implemented concurrently with the REACH curriculum during the 2017-2018 school year (late August 2017 to mid-May 2018).

The GIRL curriculum. The GIRL curriculum was semistructured and student-centered. Past research focusing on similar issues and concepts related to youth empowerment and navigating barriers to PA has shown that cocreating a curriculum can be an effective way to help girls create opportunities for PA (Oliver et al., 2009). We worked with the girls closely over the school year utilizing an approach similar to Oliver and Osterreich's (2013) model of student-centered inquiry as curriculum, which involves a cyclical process of planning, responding to students, listening to respond, and analyzing the responses. The GIRL curriculum had two goals: (a) to influence participants' lives and empower them to practice high levels of confidence and satisfaction with their bodies and (b) to provide a safe space in which girls can discuss various concerns regarding the body. All activities in the GIRL curriculum were developed to align with these goals, yet the curriculum was tailored to meet the participants' interests and desires. Therefore, the researchers checked-in with participants for feedback throughout the program and adapted the curriculum accordingly. Although the program was started by adults (two researchers), the GIRL program stemmed from a desire by young girls to have a space to discuss these issues and after the implementation began, the researchers consistently checked-in with the girls to receive feedback on how to adapt the program to fit the needs of the girls.

The GIRL curriculum was divided into four 7-week segments across the school year and was implemented using an activist approach. The first segment of the curriculum focused on introductions, trust-building activities, and effective communication strategies. Building trust and effective communication were imperative for aligning with the fourth element of the activist approach, sustained listening and responding over time. The focus of the second segment was introducing activities such as showing the girls empowering videos and engaging in magazine exploration activities (Azzarito et al., 2016; Oliver \& Lalik, 2001, 2004). This segment focused on the activist approach of embodiment. The third segment of the curriculum, a student-centered pedagogy approach, focused on providing choices to the girls for completing activities in different ways (e.g., writing or discussion), or providing activities the girls had suggested. The final segment focused on culminating activities that would make a lasting impact; this aligned with an inquiry-based education centered in action. For a more detailed description of the GIRL curriculum, see Meza and Marttinen (2019).

For the first 9 weeks, the GIRL sessions were held once a week during the first $20-40 \mathrm{~min}$ of the REACH program. Participants requested more sessions, which led to the adjustment of the GIRL sessions being held twice a week from the 10th week of implementation of the 28-week program. Bri attended all sessions throughout the year; both coaches were present for almost all of the sessions. Throughout the academic year, a total of 38 structured sessions, designed initially by the coaches then modified and redeveloped with student feedback throughout the year, were held with participants. All sessions followed a set routine. Participants joined the researchers at a table located in the same area where REACH was held. Sessions were not held in a separate room due to school district rules and limited district staffing. Each session was designed with approximately 30 min of activities; however, session lengths varied, and some activities carried into the following session. When GIRL sessions completed each day, the participants returned to REACH curriculum activities (see Meza \& Marttinen, 2019 for more information on REACH sessions).

\section{Data Sources}

Data were collected via multiple sources, including: a researcher journal, field notes and observations, participant's journals throughout the program, participant's winter break journals, semistructured interviews with students, e-mails between the after-school program coordinator and researcher, and artifacts created by participants during GIRL sessions.

Field notes were recorded by the primary researcher into a notebook during each session based on observations about behavior and dialog of the participants. The primary researcher audiorecorded specific details after each session (e.g., direct quotes from participants), and shared that with the research assistant to add to the field notes. The research assistant also observed and 
documented details from each session. In total, the researchers collected 66 pages of field notes from observations.

Participant journals served as another rich source of data. The participants completed the majority of activities by responding to a discussion topic, question, or prompt in participant journals. The participants also completed free-write journal entries and answered prompts in a "winter break journal" provided by the researchers during the 4-week break. Activities not completed within the participants' journal (i.e., worksheets) were scanned or copied to be used as an artifact. Journal entries from participants comprised 155 pages of data. Correspondence between the after-school program coordinator and district-level personnel were also saved and used as data sources. There were 90 pages of e-mail correspondence collected as artifacts.

The researchers conducted semistructured interviews with GIRL participants at the end of the school year. Participants gave assent to be interviewed, and all but one participant gave consent to be audio-recorded, resulting in eight interviews. Interviews followed an interview guide with questions designed to help understand participants' experiences in the GIRL programming. The interviews were also designed to delve deeper into conversations about body image, self-esteem, and perceived empowerment the girls experienced in the program. Interviews lasted approximately $40 \mathrm{~min}$ each (average interview length: $41.3 \mathrm{~min}$ ). All interviews were transcribed verbatim. Interview transcriptions resulted in 164 pages of data. A total of 475 pages of data were analyzed.

\section{Data Analysis}

Data were analyzed using a variety of means. First, all interviews were transcribed verbatim. Two researchers, including the primary researcher and the second author, coded the data from all sources using the constant comparative method (Glaser, 1965) utilizing open and axial coding. This allowed the researchers to constantly compare codes with themes that emerged or reoccurred from the data, and group the codes together to support those themes. The coders limited discussion during the coding process to ensure independent coding, and discussed technical concerns rather than the content of the codes. After completing independent coding, researchers formed ten emerging themes based on codes. A peer reviewer received the entire list of codes, emerging themes, top 30 referenced codes, and notes from coding. The peer reviewer had extensive qualitative research experience, knowledge of adolescent females, and pedagogical practice in urban schools and communities. After reviewing the materials, the peer reviewer and two coders discussed discrepancies within the code lists and themes. Together, the three individuals agreed on two themes that had appeared prevalently in both coders' analyses. These themes were selected based on their strength and extensive support being available from the data. In addition, the two coders and peer reviewer checked for negative cases against these themes.

\section{Trustworthiness and Credibility}

The researchers sought trustworthiness and credibility in the study by the use of a peer reviewer; implementing member checks; prolonged engagement in the community; negative case analysis; and triangulating the data using several data sources (participant journals, interview transcriptions, field notes, and artifacts). In addition, the researchers met weekly to challenge one another's thoughts and biases in team meetings. Throughout the study, the researchers ensured they actively listened to participants to better understand their interests and needs in order to create the curriculum to be student-centered.

\section{Results and Discussion}

The results of our data analysis led us to two themes that permeated the data: (a) "Boys: A barrier to PA" and (b) "Ideal female body alignment." In reading the "Results" section we would like to note that the GIRL research project was inspired from work conducted over the years by researchers Oliver, Hamzeh, Lalik, McCaughtry, and Luguetti, who worked closely with young girls in PA settings in a variety of contexts. We never assumed that the results of our study would align so closely with research that was conducted more than a decade earlier which highlighted the myriad issues young girls face to participating in PA. We address this here as we feel that although this study may appear to begin as "the same old story" or something "we already know," we argue that the meaning behind these two themes is much more complex as you will see in the following combined "Results and Discussion" section.

\section{Theme 1-Boys: A Barrier to PA}

In 2010, Oliver and Hamzeh published an article on their work with young, mostly Latina girls titled "The boys won't let us play." Oliver and Hamzeh described the participants as Borderland mestizas, referring to work by Anzaldúa (2007), who experience many different cultures, which can create "tensions that often result in girls resisting one particular label" (p. 39). In the study by Oliver and Hamzeh (2010), the girls identified boys as a barrier to PA in their PE classes. The boys would exclude the girls from playing sports because of their gender or because they were perceived to be too good or not good enough to play with the boys. The researchers worked with the participants, who were active coresearchers, to help the fifth-grade mestizas challenge PA discourse at school.

We found our first theme aligned almost directly with the findings from the Oliver and Hamzeh (2010) article. In this study, it was clear the boys acted as a barrier to girls' PA, resulting in the boys still not letting the girls play. Arguably, this could be attributed to a reality in that although plenty has been written about it (see overview in Oliver \& Kirk, 2015), PE and PA opportunities have not changed over the decade, and thus, we should not have expected drastic change. The girls often shared the experiences they had with boys during recess, lunch, PE, or after-school. The girls' interactions with boys ultimately affected their engagement in PA and experiences in PA spaces. This results in the first theme, which are described by two subthemes. The first subtheme "The boys still don't let us play" presents how the gender discourse experienced by the girls, led to the boys acting as a barrier to PA. The second subtheme explains how the GIRL curriculum attempted to redirect the girls from the gendered discourses and the common misconceptions about gender that they received in their daily lives.

"The boys still don't let us play." In our discussions, and later during the semistructured interviews, the girls would recall moments they were dissuaded from PA because of the boys. The following excerpt, from an interview with Rosa, illustrates a common occurrence between the boys and girls during after-school free play.

Rosa: I don't like to play soccer with the boys, because there's, like, you can't play because you're a girl. It's like who cares? And then, Diana plays with them, too. And then, they don't say anything to her.

Bri: So, the boys are telling you that you can't play soccer with them because you're a girl? 
Rosa: Mm hmm. Yeah.

Rosa later explained that she played basketball instead of soccer because of what the boys said and that the boys typically did not play on the basketball courts. Several data sources pointed to the fact that the girls would play basketball instead of soccer to avoid negative interactions with the boys. In addition, Rosa revealed in her interview and it was noted in Bri's field notes that, the boys allowed Diana, another girl in the group, to play because she was good at soccer. In our observations, Diana almost always played hard and aggressive on the field and was on the same skill level if not better than the boys. Similar behavior was observed by Fisette (2013), who found secondary school girls felt they needed to prove themselves to the boys and also navigated and negotiated the risk of being embarrassed while walking a fine line between "girly" and "boy-ee" activities.

Aside from being told by the boys that they cannot play, several data sources pointed out that the boys would not pass the ball to the girls during soccer; would be rough or overly competitive; and would control how the sports were being played (i.e., boys vs. girls). This resulted in the boys' behavior (e.g., playing rough) dissuading the girls from engaging in PA at school. Moreover, although many of these incidents occurred at school and were discussed in the context of playing at school (in the after-school program and at recess), Sarah discussed in her interview that she would not join a soccer team in fear of playing against others who play rough, like the boys at her school. She also explained that her dad was the only male she would play with because she knew he would not play rough. It is important to highlight that Sarah's engagement in PA was affected outside of school due to the boys' behavior in school.

Misconceptions and being redirected. Although the girls were prevented from participating in PA during recess and outside of school, the activities in GIRL attempted to help breakdown common misconceptions and redirect the girls' thoughts. Moreover, the GIRL sessions allowed the girls a place to share their experiences and educate the girls about issues of equality. The aim of the GIRL curriculum was to engage girls in discourse about body image, expose negative messaging the girls face, and explain how they can navigate this often-complicated environment. To be clear, it was not the sole mission of the GIRL curriculum to increase PA levels of the girls, the focus was on opening dialog and providing opportunities. When Bri started to use student feedback to create the curriculum that is when the girls engaged in it more. The focus of the curriculum on the girls was an important aspect of engagement.

Although it was clear the gender discourses affected the girls in some way, the GIRL curriculum attempted to redirect those discourses into something more positive. For example, on National Girls and Women in Sports Day, the coaches planned activities that allowed the girls to learn about women in sports in hope the girls would feel proud to be female and feel empowered to accomplish their own goals. The following excerpt from the field notes, documents some of the girls' responses regarding their thoughts about National Girls and Women in Sports Day.

Alexandria chimed into the conversation and said, it's "freedom for girls to be more active with sports and stuff." Bri decided to ask the girls how many of them know off the top of their heads a male athlete's name in sports more widely. Everyone raised their hand. Bri asked how many of them know off the top of their heads a girl athlete's name and no one raised their hand. Bri listed sports that girls participate in, such as basketball, soccer, softball, volleyball, and asked the girls "How can we celebrate this day?" Alexandria said, "We play sports." Catarina said, "Tell boys to tell us congrats because they don't let me play when it's soccer." During the debrief, the girls felt celebrated, yet it was clear that they did not know of female athletes as well as they knew male athletes. In addition, Catarina's comment may be interpreted as her need to be celebrated and appreciated by the boys at her school.

While the excerpt above illustrates how the girls may have been affected by the gender discourse and popularity of male sports (Connell, 2008), the GIRL curriculum attempted to redirect the common misconceptions among the girls and combat some of the negative experiences the girls had with boys. For example, the girls often discussed that during free play the boys controlled who played, what was played, and how it was played. While they were not in control of their PA spaces, the girls were able to have control in the GIRL sessions as their opinions were consistently sought after and encouraged to maintain the student-centered nature of the curriculum. The girls enjoyed being able to choose some of their activities or the topics of those activities with some flexibility as noted in the field notes from Bri: "The girls seemed excited to get the opportunity to vote for their next activity." As I passed out the prompt they started to make little comments to each other like "ooo" and "I wanna do this one." Working to empower the girls was done purposefully and with a lot of thought. Bri felt that in order to empower the girls we needed to make them feel like there is some hope and positivity in their future. "Although it is good to shed light on the disadvantages women have faced, there needs to be a balance with some of the advantages we have and about the amazing things we have done!" (Bri's field notes).

The gender discourse that permeated the girls' experiences during recess, lunch, PE, and after-school resulted in the girls being discouraged to play, excluded by the boys, or deciding to play under the boys' circumstances. This finding may highlight some concepts to consider in comprehensive school PA programs (CSPAP). For example, there is much research conducted as of late (e.g., Carson \& Webster, 2019; Chen \& Gu, 2018), but we wonder if these programs are set up to promote equal participation during the after-school setting and recess and if they have considered a format that empowers all participants to move. A further concept to consider is the fact that in the United States, Title IX forbids single-sex PE classes unless the activity is a "contact sport" such as wrestling. With that said, although we do not advocate for overturning Title IX as it has brought tremendous good through access to sports and PA for girls and women over the past 40 years, we do ask the question if there is a time where girls should be allowed to participate in single-sex PE classes if they so choose during a specific age range. This would then obviously lead to a follow-up question of how to accommodate nongender binary and trans students. This topic has been discussed in depth by Landi (2019), who argues that it is not about splitting genders apart in PE settings as much as it is about providing the choice to the student on who they choose to participate in PA with. Landi explains that PE and PA focus on the body, and therefore, it produces more pressure to the students who have nonnormative bodies. The focus should be more on allowing the students to choose a more comfortable environment to participate in and not relying on adults, teachers, or policymakers to make the choice for them. The girls in our study were found to be much more active and social when among girls only. We were able to circumvent bans for single-sex PA as we were framed within an after-school setting, not in a public elementary PE class. 


\section{Theme 2: Alignment With the Ideal Female Body}

The second theme revolves around the female beauty ideal (BakerSperry \& Grauerholz, 2003) and illustrates how girls aligned with that notion. Yet, contrary to previous research (Oliver et al., 2009), the girls were able to combat this view and not use certain concepts such as hair and makeup as barriers to PA. This is not to say the concepts of the female beauty ideal did not exist within these girls. The girls still often aligned with the stereotypical views of beauty (e.g., straight hair, skinny, nice eyebrows) as noted in many of the assignments and conversations within GIRL (Azzarito, Simon, \& Marttinen, 2017; Azzarito, 2009). There were efforts in combating this. When Bri worked to present critical thinking exercises to combat perceptions of traditional gender roles, girls when asked in sessions, often defaulted to comment on beauty in traditional ways. Theme two discusses first the stereotypical views of beauty that the girls brought up. Second, we present what we see as the first ripple in change from years of previous research, which has shown that girls align with stereotypical views of female beauty (BakerSperry \& Grauerholz, 2003), and conversely show, through our results, how the body-positive movement (Sastre, 2014) has made a change in how girls perceive themselves. Finally, the last part of theme two discusses the instances where girls described how being a "girly girl" was not a barrier for girls PA, which allows for some comparison to past research (Oliver et al., 2009).

Girls and stereotypical views of beauty. In many of the activities where students in GIRL were asked to examine images of celebrities (from popular magazines and screen shots of celebrity social media posts), the girls often commented on how pretty the women were. The benefit of using student journals with the girls was that the researcher could engage in an informal back and forth conversation to challenge these gender norms and beauty ideals in a private manner. Journal prompts ranged from a "rose and thorn" activity where students discussed one positive moment of their school day and one negative moment, to having them reflect on videos they saw during GIRL sessions or asking them which celebrities the girls look up to and why.

For instance, when a student discussed a favorite celebrity of hers, Miranda Sings (a YouTube personality) as pretty and funny, Bri was able to comment back in her journal to probe if she thought that Miranda Sings was popular due to her being pretty or funny. Maria replied that it was due to her humor, which may have been due to the student trying to say the "right thing" to Bri yet demonstrates one tiny example of a year-long effort by Bri to consistently challenge the thinking of the students. This was not done in a way to make the student feel that they are making the "wrong" decision, but more so challenging them to critically analyze why the girls were making the comments they were making about beauty.

Other girls still aligned with the stereotypical views of how to be beautiful as is noted in this journal entry by Emmelina "Beauty means putting make up on and what it looks like is beauty." This negative case to our initial theme is troubling to us as researchers yet is important to address. Although Bri and Olivia consistently worked to have students question their beliefs of what gender norms were and who is beautiful and why, the stereotypical views of beauty permeated the lessons.

"Beauty comes when you just be yourself." Beauty was a common discussion topic in the sessions with the girls. Bri and Olivia consistently challenged traditional gender norm beliefs of the girls, but more so we were surprised with how much of an influence the Internet and social media had on the girls' beliefs. We were actually pleasantly surprised at how much of this movement was based in positive language, positive messages about beauty and bodies.

A frequent comment that was heard in conversations and through journals and written assignment was this notion of "just be yourself." When Paulina was asked to elaborate on her journal entry she responded, "Because, sometimes I see people, like, they're competing to be the best and to be the more pretty." Bri followed up and asked why Paulina thought girls would do this, and Paulina replied, "Because maybe they like the same boy." Finally, following up with Paulina about why she wrote "be yourself" in several journal entries she responded, "Because, I don't want to change anything (about her body)." This comment demonstrates strong body image and body confidence, and interestingly aligns with the body positive movement that has grown on social media and the Internet more widely (Sastre, 2014). However, as we note below, young people are increasingly turning to social media for health-related information on diet and nutrition facts and body image (Goodyear, Armour, \& Wood, 2019).

Social media impacted the way students discussed beauty and bodies. A comment in a journal by Maria discussed how she saw many celebrities on SnapChat (a social media platform focused on videos) with makeup on, but simultaneously commented that many celebrities also did not wear makeup. Other comments about beauty reflected a wider description of beauty, and not just having pretty hair, being skinny, and White (Azzarito, 2009). Emmelina wrote in her journal about how she viewed a picture from a magazine "what I like about the women is that in the picture she looks really brave and really healthy, also beautiful." Emmelina focused on not just the woman's hair and makeup, but also how she depicted being brave and healthy. Instances like this popped up through many other comments that still aligned with the female beauty ideal as many of the girls still commented on how they wanted to have similar cheek bones, hair, and eyebrows as the celebrities in the photos. Comments within the journals included "I like her eyebrows," "I like her hair it is a light color (blonde)," "I like her hair on Instagram," and "beauty means putting make up on." Girls did not comment, however, on the weight of the girls very often at all. Much of the commentary revolved around makeup, the straightness of the celebrity's hair, and their facial structure. Yet, it was very infrequent that the girls would say they liked an image of a woman because she was skinny.

The evolution of the "girly girl." In landmark research by Oliver et al. (Oliver \& Hamzeh, 2010; Oliver et al., 2009), they discuss indepth experiences working with Mestiza girls and their experiences in PE. In Oliver et al.'s (2009) paper, being a "girly girl" was cited as a reason the girls as not being physically active in PE (according to their teachers). In our research with the girls in this project, we found that being a girly girl was not as much of a barrier to PA.

One reason that the girls may not have faced the same barriers to PA could be the intentional structure of the GIRL sessions. The girls were in an all-girl group and strengthened relationships through the program. The girls mostly enjoyed the sessions that Bri and Olivia co-planned with the students as is demonstrated from this excerpt from Olivia's field notes:

I felt that the most fun the students had was during this activity (Social Scenarios) because they began to express interest in doing this activity multiple times. Mainly because they were able to work together with their friends, solve the problem, and perform it in front of their peers. At the end of each performance, we had a chance to discuss the scenario and ask the other girls if they would have done the same thing or what they would do differently.-Olivia 
The quote above displays what an important concept providing a safe place to think critically, and be physically active with friends is. Other girls like Emmelina said that they enjoyed the sessions because they were able to express themselves. Others like Elena explained during her interview that she enjoyed that she was able to have a choice in activities and liked participating in physical activities with her girlfriends. Providing a physically and emotionally safe space to be physically active does mirror the findings of Oliver et al., who were able to provide a space for the girls to create their own games.

Another reason why girls participated at much higher levels in the activities may have been the connection they were able to make with the GIRL coaches. When asked in an interview why Alicia felt comfortable sharing her thoughts with the coaches she said, "because you guys are, like, girls, so, like, I would feel uncomfortable to say it to Coach Roberto and stuff. But, like, for you guys, you guys, like, you guys understand how we feel, because you guys been through it before, so ..." So, although Alicia ironically referred to Bri and Olivia as "guys" five times in two sentences, she explained that a female role model was meaningful for her and provided her a person to reach out to about matters that were important to her.

It is important to note that Oliver et al. (2009) did find that when they worked specifically with the girls in a setting outside of normal PE class, the girls actually were able to negotiate the ways in which they chose to be physically active. An argument could be made that PE, and therefore PE teachers, could be a barrier to PA for some populations. Oliver et al. were able to work away from the normally structured PE class with girls in small groups and actively involve those students in the decision-making process. However, recent work by Oliver and Kirk (2015) among others working in after-school environments (Enriquez, 2019; Luguetti et al., 2017) have shown that utilizing activist approaches could solve this issue and showed that the approach is feasible beyond just small groups of children. Going back to the Oliver et al. (2009) study, some days the girls chose activities that did not make them sweat, and on others, the girls designed activities that were more vigorous. This act of choosing when to be physically active vigorously and when not to is mirrored in our study in the example below from Diana.

Diana was the most active with the boys and frequently was the only girl playing soccer with the boys. Diana came to the United States as an immigrant at the beginning of the school year when GIRL started. She spoke little English at the start of the year, but as many youth at this age do, her language acquisition grew tremendously over the year. In the beginning, Diana communicated with Risto and Olivia through Spanish and through informal translators from the other girls in the group. An excerpt from Bri's field notes describes what the coaches felt was a strange reversal of behavior from Diana. "Diana didn't want to play because she was in a dress for picture day. At this point I (Bri) felt like there was no convincing her so I allowed her to sit out for the game." Diana is described in other field notes as the only girl playing with the boys and playing to the aggressive level that the boys often played and not shying away from body contact or hard kicks. Thus, it was interesting that on this one day, she refused to participate as she was wearing a dress for picture day. This highlights the proverbial tide of change where the majority of the time the girls bucked the trend reported in past research (e.g., Oliver \& Hamzeh, 2010) yet swayed back to realign that same research in a different session alluding that things have not necessarily changed all that much. These instances cannot be isolated into single events as they do not tell the complete story. Without prolonged engagement with the girls in this program, we feel we would not be able to tell the full story of how the girls navigated complex social scenarios, gender norms, and influences of social media on the girls' thoughts and behaviors.

\section{Conclusion}

The purpose of this article was to explore how the GIRL curriculum, implemented over a school year with fifth- and sixth-grade girls, engaged participants in critical analysis of the ideal female body and helped girls identify perceived barriers to PA. The first finding from our research identifies the continuation of male dominance in this setting (a long-standing and institutionalized concern), and boys acting as barriers to PA (Oliver \& Hamzeh, 2010). As educators and researchers, it is frustrating to see that despite a wealth of research related to disparities in PA levels among boys and girls (Clark, 2015; Roth et al., 2019) and the call to meet the needs of all students (Azzarito et al., 2017; Oliver et al., 2009), PA opportunities (at least in this context) have not evolved much over the last decade. Educators wishing to address issues of social justice are faced with the task of creating an environment to empower students, recognize and disrupt instances where particular identities or roles oppress those with less power or privilege, and challenge these circumstances (Bell, 2016; Hytten \& Bettez, 2011; Walton-Fisette \& Sutherland, 2018). We suggest that teacher preparation programs and program administrators (for PE programs and school-based PA programs) critically examine their practices and policies to prepare teachers who can provide more equitable programming for students.

The second finding of our research does suggest that youth may have more positive role models and receive messages from social media and other outlets that promote a more body-positive philosophy (Sastre, 2014). This refreshing finding gives us hope that those who self-identify as "girly girls" can critically critique celebrities and navigate social media while still seeing plenty of examples of role models who are athletic, confident, and beautiful by the standards of the youth who look up to them.

\section{References}

Anzaldúa, G. (2007). Borderlands/LaFrontera: The New Mestiza. San Francisco, CA: Aunt Lute Books.

Azzarito, L. (2009). The Panopticon of physical education: Pretty, active and ideally white. Physical Education and Sport Pedagogy, 14(1), 19-39. doi:10.1080/17408980701712106

Azzarito, L., \& Hill, J. (2013). Girls looking for a 'second home': Bodies, difference and places of inclusion. Physical Education and Sport Pedagogy, 18(4), 351-375. doi:10.1080/17408989.2012.666792

Azzarito, L., Macdonald, D., Dagkas, S., \& Fisette, J. (2017). Revitalizing the physical education social-justice agenda in the global era: Where do we go from here? Quest, 69(2), 205-219. doi:10.1080/00336297. 2016.1176935

Azzarito, L., Simon, M., \& Marttinen, R.. (2016). 'Stop photoshopping!': A visual participatory inquiry into students' responses to a body curriculum. Journal of Teaching in Physical Education, 35(1), 54-69. doi:10.1123/jtpe.2014-0166

Azzarito, L., Simon, M., \& Marttinen, R.. (2017). "Up against Whiteness”: Rethinking race and the body in a global era. Sport Education and Society, 22(5), 635-657. doi:10.1080/13573322.2015.1136612

Azzarito, L., \& Solomon, M.A. (2005). A reconceptualization of physical education: The intersection of gender/race/social class. Sport, Education and Society, 10(1), 25-47. doi:10.1080/135733205200028794 
Azzarito, L., \& Solomon, M.A. (2006). A poststructural analysis of high school students' gendered and racialized bodily meanings. Journal of Teaching in Physical Education, 25(1): 75-98. doi:10.1123/jtpe. 25.1.75

Baker-Sperry, L., \& Grauerholz, L. (2003). The pervasiveness and persistence of the feminine beauty ideal in children's fairy tales. Gender \& Society, 17(5), 711-726. doi:10.1177/0891243203255605

Bell, L.A. (2016). Theoretical foundations for social justice education. In M. Adams, L.A. Bell, D.J. Goodman, \& K.Y. Joshi (Eds.), Teaching for diversity and social justice (pp. 3-26). Abingdon, UK: Routledge.

Carson, R., \& Webster, C.A. (Eds.). (2019). Comprehensive school physical activity programs: Putting evidence-based research into practice. Champaign, IL: Human Kinetics Publishers.

Chen, S., \& Gu, X. (2018). Toward active living: Comprehensive school physical activity program research and implications. Quest, 70(2), 191-212. doi:10.1080/00336297.2017.1365002

Clark, S. (2015). Running into trouble: Constructions of danger and risk in girls' access to outdoor space and physical activity. Sport, Education and Society, 20(8), 1012-1028. doi:10.1080/13573322. 2013.866548

Connell, R. (2008). Masculinity construction and sports in boys' education: A framework for thinking about the issue. Sport, Education and Society, 13(2), 131-145. doi:10.1080/13573320801957053

Cothran, D.J., \& Ennis, C.D. (1999). Alone in a crowd: Meeting students' needs for relevance and connection in urban high school physical education. Journal of Teaching in Physical Education, 18(2), 234-247. doi:10.1123/jtpe.18.2.234

Enriquez, O.N. (2019). 'Can we play the real sport?': The process of co-creating a sustainable student-centered after-school sports club (Doctoral dissertation). New Mexico State University, Las Cruces, NM.

Fisette, J.L. (2013). “Are you listening?”: Adolescent girls voice how they negotiate self-identified barriers to their success and survival in physical education. Physical Education and Sport Pedagogy, 18(2), 184-203. doi:10.1080/17408989.2011.649724

Fitzgerald, H. (2005). Still feeling like a spare piece of luggage? Embodied experiences of (dis)ability in physical education and school sport. Physical Education and Sport Pedagogy, 10(1), 41-59. doi:10.1080/ 1740898042000334908

Gavey, N. (1989). Feminist poststructuralism and discourse analysis: Contributions to feminist psychology. Psychology of Women Quarterly, 13(4), 459-475. doi:10.1111/j.1471-6402.1989.tb01014.x

Glaser, B.G. (1965). The constant comparative method of qualitative analysis. Social Problems, 12(4), 436-445. doi:10.2307/798843

Goodyear, V.A., Armour, K.M., \& Wood, H. (2019). Young people and their engagement with health-related social media: New perspectives. Sport, Education and Society, 24(7), 673-688. PubMed ID: 31814804 doi:10.1080/13573322.2017.1423464

Hytten, K., \& Bettez, S.C. (2011). Understanding education for social justice. Educational Foundations, 25(1-2), 7-24.

Lamb, C.A., Oliver, K.L., \& Kirk, D. (2018). 'Go for it Girl' adolescent girls' responses to the implementation of an activist approach in a core physical education programme. Sport, Education and Society, 23(8), 799-811. doi:10.1080/13573322.2018.1484724
Landi, D. (2019). LGBTQ Youth, physical education, and sexuality education: Affect, curriculum, and (new) materialism (Doctoral dissertation). The University of Auckland, NZ.

Luguetti, C., Oliver, K.L., Kirk, D., \& Dantas, L. (2017). Exploring an activist approach of working with boys from socially vulnerable backgrounds in a sport context. Sport, Education and Society, 22(4), 493-510. doi:10.1080/13573322.2015.1054274

Meza, B., \& Marttinen, R.. (2019). The GIRL Curriculum: Co-constructing learning about body image through empowering after-school programming. Journal of Youth Development, 14(4), 216-231. doi:10.5195/jyd.2019.771

Oliver, K.L., \& Hamzeh, M. (2010). "The boys won't let us play": 5 th grade mestizas publicly challenge physical activity discourse at school. Research Quarterly for Exercise and Sport, 81(1), $39-51$.

Oliver, K.L., Hamzeh, M., \& McCaughtry, N. (2009). Girly girls can play games/Las ninas pueden jugar tambien: Co-creating a curriculum of possibilities with fifth-grade girls. Journal of Teaching in Physical Education, 28(1), 90-110. doi:10.1123/jtpe.28.1.90

Oliver, K.L., \& Kirk, D. (2015). Girls, physical education and gender: An activist perspective. London, UK: Routledge Publishers.

Oliver, K.L., \& Lalik, R. (2001). The body as curriculum: Learning with adolescent girls. The Journal of Curriculum Studies, 33(3), 303-333. doi:10.1080/00220270010006046

Oliver, K.L., \& Lalik, R. (2004). "The beauty walk, this ain't my topic:" Learning about critical inquiry with adolescent girls. The Journal of Curriculum Studies, 36(5), 555-586. doi:10.1080/00220270 32000139397

Oliver, K.L., \& Osterreich, H.A.. (2013). Student-centred inquiry as curriculum as a model for field-based teacher education. Journal of Curriculum Studies, 45(3), 394-417.

Quarmby, T., \& Dagkas, S. (2013). Locating the place and meaning of physical activity in the lives of young people from low-income, lone-parent families. Physical Education and Sport Pedagogy, 18(5), 459-474. doi:10.1080/17408989.2012.690384

Roth, S.E., Gill, M., Chan-Golston, A.M., Rice, L.N., Crespi, C.M., Koniak-Griffin, D., ... Prelip, M.L. (2019). Physical activity correlates in middle school adolescents: Perceived benefits and barriers and their determinants. The Journal of School Nursing, 35(5), 348-358. PubMed ID: 29895181 doi:10.1177/1059840518780300

Sastre, A. (2014). Towards a radical body positive: Reading the online "body positive movement". Feminist Media Studies, 14(6), 929-943. doi:10.1080/14680777.2014.883420

Vertinsky, P.A. (1992). Reclaiming space, revisioning the body: The quest for gender-sensitive physical education. Quest, 44(3), 373-396. doi:10.1080/00336297.1992.10484063

Walseth, K., Engebretsen, B., \& Elvebakk, L. (2018). Meaningful experiences in PE for all students: An activist research approach. Physical Education and Sport Pedagogy, 23(3), 235-249. doi:10.1080/ 17408989.2018.1429590

Walton-Fisette, J.L., \& Sutherland, S. (2018). Moving forward with social justice education in physical education teacher education. Physical Education and Sport Pedagogy, 23(5), 461-468. doi:10.1080/ 17408989.2018.1476476 